\title{
Cognitive and Affective Processes in Collection Development
}

\section{By Brian Quinn}

The selection process in collection management has been characterized as based primarily on logical, rational thinking processes. Psychologists, however, have discovered that judgment and decision making are not exclusively cognitive functions. They depend instead on a complex interaction between affect and cognition, feeling and thought. This paper attempts to explore some of these interactive processes and how they potentially influence the selection process in collection development. Some implications for how selectors approach their work are discussed as well.

any of the most important decisions that are made in libraries involve colI lection development and management. Decisions about whether to add new titles or to cancel existing ones are often complicated and stressful because they frequently involve the commitment or redistribution of limited funds. Often the outcome of the decision affects not only librarians but also stakeholders outside the library. For academic libraries, these constituents include faculty, students, and sometimes the community. Decisions by public and school librarians are often made with parents, school boards, library trustees, and municipal officials in mind.

Given its importance, librarians have attempted to analyze the process of decision making for collection development. This process has been depicted in the library literature as being a thoughtful, reasonable, rational one that is fundamentally logical and deliberative. Psychologists have examined decisionmaking processes in much more depth and detail than librarians. The psychological literature indicates that decision making is not simply a cognitive or thinking process. Rather, it depends to a significant extent on affect or emotion. The purpose of this paper is to examine the psychological research on decision making and explore the implications of revisioning collection development decisions as being not simply matters of the head but also matters of the heart.

Standard works on collection development generally depict the selection process as a mental process but not an emotional one. Hamlin states that selection requires the selector to understand the needs of the user and know which resources to consult to locate appropriate material. ${ }^{1}$ The selector must be able to differentiate suitable sources from unsuitable ones, and evaluate the quality of the materials. The decision-making process also involves being able to reconcile the amount and cost of the material under consideration with the budget that the selector has to work with. A selector also needs to be aware of how much material the library already owns on a topic and whether further material is needed, and also if similar material may be available in a nearby collection. The selection

Brian Quinn (brian.quinn@ttu.edu) is Social Sciences Librarian and Coordinator of Collection Development at Texas Tech University, Lubbock. process that Hamlin depicts is thus exclusively cognitive, with no reference to affect or emotion. 
A similarly strong emphasis on the cognitive aspects of decision making can be found in Atkinson's hypothetical model of the selection process. ${ }^{2}$ Selection decisions are based on the context in which the selector places a work. The elements of the citation itself, such as author, title, publisher, and date, provide the syntagmatic context. The ability to recognize these elements and how they influence one another is an important aspect of the selector's thought process in decision making. Additional cues that help the selector evaluate the work are subject headings, annotations, reviews, the work itself, and the user, which are referred to as the contexts of supplementation. Recognizing the importance of other citations that may be found with the citation in question and the source in which the citations are found may provide indirect supplementation. The third context is known as the contexts of resolution, which itself includes three contexts. The first of these, the archival context, refers to the selector's understanding of what is already available in the collection. The communal context is based on the selector's knowledge of the needs and interests of the community of users being selected for. The thematic context involves the selector's understanding of publication trends in the subject matter. The final decision-making process consists of the selector connecting or relating the elements of the citation to the source and to the contexts of resolution. The core mental processes mentioned in this model-recognition, understanding, and relating-are cognitive or thinking processes. Affect or emotion does not seem to play a role.

Although less theoretical than Atkinson's model of selection, the six categories of selection criteria proposed by Rutledge and Swindler are similarly cognitive. ${ }^{3}$ These include discerning the subject of a work, evaluating its intellectual content, predicting the amount of use a work will get based on the selector's knowledge of users, understanding how the work relates to the rest of the collection, bibliographic considerations such as reputation of the publisher, format of the material, and language of the work. To further rationalize the selection process, the authors prioritize the criteria and refine the process by creating three priority levels: the library must, should, or could add the title. They then attempt to quantify the model so that each criterion receives a weighting based on its overall importance and each title can then be given a numeric score. In this model, selection is reduced to a rational calculus, a precise science devoid of any affective dimension. Although they characterize their model of selection as "holistic," it is exclusively based on a reasonable, rational, mental model that seems reductionist because it does not take into account emotional processes.

In her book, The Decision-Making Process for Library Collections: Case Studies in Four Types of Libraries, Kovacs attempts to identify the thought processes involved in selection by categorizing them according to seven routines: recognition, diagnosis, search, design, screening, evaluation/ choice, and authorization. ${ }^{4}$ The kinds of thought processes she describes, however, are cognitive. Recognizing gaps in the collection, searching catalogs, and scanning reviews, determining the characteristics of materials needed, identifying the optimal way to obtain the material, identifying the most effective source, making a final evaluation of the source, and then authorizing it, are all processes that involve thinking rather than affect or feeling. Kovacs advises selectors that they need to avoid unconscious decisions, and that selection is based on awareness of needs and materials rather than intuition. Her model emphasizes cognitive processes to the exclusion of affective ones.

Mental processes related to decision making in the selection process are described by Williams, who believes that a selector must possess the ability to recognize important works in a field, which she labels a cognitive skill. ${ }^{5}$ She describes recognition as a function of memory and discusses various psychological theories of how memory works. Williams suggests that novice selectors create written lists of canonical authors and works to prime their memories for recognition of important works. The author draws openly from the literature of cognitive psychology in describing schema theory and how a selector's prior knowledge will improve the ability to recognize and recall information about related material. She makes no mention of affective processes in her model.

The highly rationalized, cognitive model is perhaps carried to its extreme in the optimalized model of decision making outlined by Losee. ${ }^{6}$ He draws upon logic, mathematics, and economics to suggest that materials selection could be computerized and done by a machine. He notes that human decision making may not be completely rational and that selectors may engage in satisficing behavior that, while not optimal, is adequate enough to meet a certain standard established by the selector. Optimal selection decisions are rational ones that result in titles of maximal utility to the user, and selectors can estimate the probability of a title's value from the reputation of the publisher, the author, or from reviews. This model relies heavily on formal reasoning and logic and does not acknowledge any emotional or affective dimension of human behavior.

In his book, Developing Library and Information Center Collections, Evans outlines a system of thinking that he recommends selectors use for each title. ${ }^{7}$ It is a series of questions the selector asks him- or herself, which includes questions about whether the subject of the title falls within the scope of the collection, whether it is of interest to the library's users, how much similar material the library already owns, whether the price of the title is within the selector's budget, what the reputation of the author or publisher is, and whether the source of information describing the title is valid. The overall approach is a systematic and logical one 
based on cognitive thought processes rather than affect. The Evans model outlines a process of thinking through the significance of a title, and there is no reference to emotion.

A similar approach to selection is taken by Clayton and Gorman in their work, Managing Information Resources in Libraries: Collection Management in Theory and Practice. ${ }^{8}$ In addition to listing some basic criteria for selection, such as author, scope and treatment of the work, organization, and format, they also discuss some general principles related to the selection process. A selector must keep informed about the selection process itself by continually reading the library literature. The critical factor in effective selection is a thorough understanding of the library's goals, the collection, and those who use it. The selector should have a firm grasp of how publishers and booksellers operate, and learn the reputation of each. Becoming familiar with sources of reviews and the reviews themselves is important, along with knowledge of bibliographies. Well-researched and independent decisions are a goal to be strived for consistently and can be achieved by following these principles. The emphasis of the authors on learning, understanding, and knowledge would suggest that they see selection decisions as cognitive in nature. No reference to emotion or affect is included in their explanation.

Knowledge alone does not result in skilled selection; experience and intuition also play a role according to Johnson in her book, The Fundamentals of Collection Development and Management. ${ }^{9}$ However, knowledge in the form of familiarity with selection tools, as well as understanding the goals of the library and the needs of its users, is fundamental. Other kinds of knowledge, such as familiarity with collection-development policies and with the subject areas being collected are also basic. Drawing on Peter M. Senge's distinction between learning and mastery, the author believes that collection-development skills can be learned, but that mastery only occurs with practice. ${ }^{10}$ The beginning selector must make a diligent and continual mental effort to learn and follow correct practices before they become automatic or unconscious. Over time the practices become so internalized that they are no longer conscious but become subliminal and effortless. The emphasis on knowledge, skills, theory, and practice indicates that this is primarily a cognitive model, and that emotion or affect is not a factor.

Making decisions about whether to purchase a book, cancel a journal, or add a database or aggregated package is often fraught with uncertainty and ambiguity. Except in rare instances in which a title obviously fills the need of a faculty member or student, the subject selector will face a host of questions that are not always easily answered. Who will use the resource? How frequently will it be used? Will users like it? Could the funds be better spent on a different resource? Does it fill a gap in the collection? Which format is best? How does it compare with similar titles? A selector may have difficulty processing the many variables and doing so quickly.

Given the high level of uncertainty inherent in making collection management decisions, the process cannot be regarded as strictly logical, analytical, and rational. A significant element of subjectivity and guesswork makes collection development decisions vulnerable to typical human shortcomings such as emotion, bias, impulsivity, and caprice. In order to avoid mental overload and fatigue caused by trying to take into account all the factors that should be considered in making good decisions, psychologists have discovered that people make use of heuristics, which are cognitive shortcuts or rules of thumb designed to simplify and expedite the decision-making process.

Such simplifications can lead to cognitive biases. For example, a selector might encounter two resources that have similar content and format, but one is more expensive. If the selector believes that the higher in quality a resource is, the more expensive it will be, he or she may decide to purchase the more expensive resource. Biases may be affective as well as cognitive. People, experience, events, and objects are embedded in memory and are emotionally charged or vested with positive or negative associations and feelings. If a selector encounters a title having to do with structural equation modeling, and he or she has read books before on this topic and found them to be boring or poorly written, the memory of those experiences along with the negative emotions associated with them may predispose the selector to be reluctant to select the book or to select related titles for the collection. ${ }^{11}$

This suggests that the decision-making process in collection development is not only not exclusively logical or rational; it is also not simply cognitive. In addition to thinking or cognition, emotion or affect is also involved. The relationship between these two psychological factors is a subject that has attracted the attention of psychologists and philosophers as far back as Plato and Aristotle. These early Greek thinkers tended to consider reason-their term for cognition—as being in conflict with passion, which was the ancients' equivalent of affect.

Plato thought that reason was the higher of the two functions. In his view, reason served to keep passion under control. Aristotle took this idea even further by suggesting that passion depends on reason. He defined anger, for example, as a form of belief that one was being treated unfairly. ${ }^{12}$ An emotion such as anger is thus the result of certain thoughts or cognitions that may ultimately lead to aggressive behavior.

The debate over the relationship between cognition and affect continues among psychologists and philosophers. Psychologists have recently shown a growing interest in the role of emotion in the decision-making process. Some 
researchers now believe that affect not only influences cognition, but that emotions steer cognitive activity in particular directions. Affect predisposes thought toward certain emotionally congruent interpretations, plans, and actions. ${ }^{13}$ As a selector thinks through a collection-development decision, his or her thoughts may be influenced toward a particular outcome as a result of experiencing a particular emotion or mood.

\section{Research on Affect and Decision Making}

Psychologists have compiled a variety of experimental evidence that suggests ways in which emotions may influence decisions. One such experiment involved 165 undergraduate students who were asked to decide whether they wanted one of two snacks as a reward for participating in the study: a piece of chocolate cake with cherry topping or a fruit salad. ${ }^{14}$ Before choosing, the students were divided into two groups. One group was asked to memorize a seven-digit number and the other, a two-digit number. The results of the experiment indicated that the students who were required to memorize the seven-digit number chose the chocolate cake, while the students who memorized the two-digit number chose the fruit salad. The researchers who conducted the experiment saw this as an indication that when students' cognitive-processing resources were consumed by having to memorize the seven-digit number, they made their decision based on affective reactions and chose the chocolate cake. Their impulsive emotional side was able to gain the upper hand in the decision-making process because their rational analytical side was preoccupied with remembering the seven-digit number. On the other hand, the students who only had to memorize the two-digit number had more cognitive resources available to analyze their decision more thoroughly, enabling them to make a prudent, rational, sensible choice of the healthier fruit salad.

The results of the experiment have interesting implications for collection development. The experiment suggests that librarians should tend to make more prudent selection decisions to the extent that they base their decisions on cognition rather than affect. Any aspects of work that are allowed to interfere with cognitive processing such as competing demands, deadlines, or budget concerns may be likely to result in poorer quality, more affect-based decisions. Selection that is affect-based is more likely to involve irrationality and impulsivity, which generally results in poor choices. The selection process in collection development, thus, may be only a logical, rational, analytical process to the extent that cognitive resources are available and are not consumed by other tasks or issues.

\section{Emotions, Moods, and Decisions}

Psychological research suggests that different types of affect have different kinds of effects on cognition. An important distinction is how emotions differ from moods. Emotions generally tend to be relatively brief but strong emotional states that are easily recognizable and have an identifiable origin and significant cognitive associations such as precipitating incidents and strategies for what to do. Moods, in contrast, tend to be less intense, less focused on a particular incident, and longer in duration than emotions. One is more likely to be in a good mood or bad mood without readily being able to attribute the mood to a particular cause. Selectors need to pay attention to their mood states when making collection-development decisions. Individuals tend to be less conscious of their moods and do not monitor them as closely as emotions, so that the effects of moods on decision making can be more subtle but also more sustained and more significant precisely because they are less subject to a person's awareness. Emotions and moods also affect one another. ${ }^{15}$ Strong emotions can leave a person in a particular mood after they subside, just as a particular mood can predispose someone to certain kinds of emotional reactions.

Affect is important to cognition in decision making because it influences what and how people think. Psychologists suspect that positive moods may serve to compromise decision making by reducing the attentional capacity of the person. Positive moods may also activate positive memories and associations that serve to distract a selector from pertinent information about a title. Individuals in a positive mood may also consciously seek to maintain this pleasant state by seeking to avoid any information that may introduce critical, negative elements or require mental exertion or complicated cognitive processing. The amount of concentration necessary to make a careful considered selection may not be compatible with feeling good. ${ }^{16}$ From an evolutionary standpoint, positive moods may reduce cognitive activity because they indicate to the brain that one can relax and feel protected, while negative moods may trigger a call for alertness or vigilant thinking. A combination of these processes may be involved, depending on the particular situation.

Extrapolating from this, it seems plausible that the more positive a selector's mood, the more likely it is that the person will adopt a superficial, disengaged process of approaching a collection-development decision. Happy selectors will tend to downplay the complexity of the decision and make use of mental shortcuts or generalizations. They will tend to make decisions more quickly and may not bother to consider all the factors that may be involved in making a decision. They may not make the effort to scrutinize a title carefully, so that any shortcomings are more likely to be revealed. 
Affect may influence cognitive processes that are important to decision making in other ways, such as memory. Memory is important to decision making because selectors use it to inform decisions. Selectors often draw on past experience to make decisions which may include subject knowledge or knowledge about librarianship, and it is memory that plays a critical role in supplying this information. The affective state of an individual tends to facilitate the recall of emotionally-congruent material stored in the person's memory. ${ }^{17}$ The selector who is in a negative mood and feeling depressed or anxious may more readily recall negative reminiscences because they match his or her emotional state.

In a study conducted of college students, participants were asked to study words with positive, negative, or neutral associations. ${ }^{18}$ They were then asked to produce associations to the material they had studied. Students not only recalled more studied than nonstudied words, but depressed students produced more associations to negative words, while nondepressed students remembered more positive words. Mood-congruent memory has been found to work not only with depressed individuals but also with natural mood states that people experience in their everyday lives. ${ }^{19}$

\section{Affect, Attention, and Judgments}

Evidence from several psychological experiments suggests that affect may play an important role in what subjects attend to. Emotion and mood can serve an orienting function by channeling attention toward or away from various environmental stimuli. People attend to stimuli selectively, and objects that are emotionally significant are given priority in the competition for attention.

This suggests that affect determines whether a given object is emotionally important. In one psychological experiment, participants rated happy, sad, or neutral pictures presented to them by an experimenter who was in either a neutral, happy, or sad mood. ${ }^{20}$ When participants were shown the pictures, those who were exposed to the happy experimenter spent more time looking at the happy pictures. Those exposed to the sad experimenter focused more on the sad pictures. When asked to rate the pictures, participants exposed to the happy experimenter gave more positive ratings. Participants exposed to the sad experimenter gave more negative evaluations. Exposure to the neutral experimenter had no effect on how much time the participants spent looking at neutral pictures or how they rated them. Affect influenced attention and also played a role in the memory of the participants. Participants recalled more pictures that matched their mood, and those participants exposed to the sad experimenter also suffered from impaired memory. This is how sadness typically affects the ability of a person to remember. The results of the experiment indicate that affect is an important factor in attention, decision making, and memory.

The experiment has several implications for collection development. It suggests that selectors will be more likely to notice and attend to particular titles or products that match their emotional state. The selector for literature who happens to be in an upbeat mood may find Tom Stoppard's comedies more interesting purchases for the collection than those of Eugene O'Neill. The selector might rate them more highly or as more necessary to the collection or a better value. Particular titles by Stoppard may be more easily recalled than those of O'Neill. Another example might be the selector for psychology who may be in a melancholy frame of mind. For this selector, titles having to do with depression may seem a more compelling purchase choice than those dealing with other topics. These examples suggest how affect might play a role in the crucial cognitive processes such as selection and evaluation, which are part of collection development.

Affect may play a role in how people respond to products, and how they respond to the way in which those products are marketed. Different types of moods may help to determine how individuals react to the way in which titles are advertised. In an experiment designed to test the effect of mood on receptivity to advertising, 120 university students were given either a happy or sad story to read, designed to induce either a positive or negative mood. ${ }^{21} \mathrm{In}$ order to help them become aware of their mood, they were then asked to record the feelings that the story produced in them as they read it. The subjects were then given either an emotional or an informational ad for cookies. The emotional ad showed a group of people at a party enjoying cookies in the background, with a colored plate of the cookies in the foreground. The informational ad featured a color photo of the cookies with ten lines of advertising copy describing the brand. Subjects were asked to read the ad they were given and then complete the questionnaire designed to measure how the subjects felt about the ad. The results of the experiment indicated that subjects who were induced into a positive mood reacted more favorably to the emotional ad. Subjects who had been placed in a negative mood were more favorable to the informational ad. The experimenters explained the results by suggesting that the more serious fact-based ad may have been perceived by happy subjects as excessively somber and dry. In contrast, subjects in a negative mood may have resented the emotional ad because it depicted a group of people having a good time and enjoying themselves.

This suggests that selectors may react favorably or unfavorably to how a title is advertised, depending on their mood. Advertising for books, journals, databases, and electronic products has becomes increasingly sophisticated. It 
has evolved from a largely rational informational mode into more emotional and image-based appeals. Whether this trend proves to be effective may depend on how selectors are feeling at the time of selection. For those vendors that use a combination of both emotional and informational appeals, it may depend on how the mix affects a given selector. Product content alone may thus not be the only factor influencing a selector's decision. How a title is presented may also play a role.

Mood may also influence decision making in another way. In one study, when research participants were asked to make a judgment about whether to purchase a car, they readily did so. ${ }^{22}$ But when the information presented about the car was difficult to understand or was sketchy, respondents tended to rely on contextual cues in order to arrive at a decision. The contextual cue that they relied on most was their mood. Mood may become a particularly important factor with complex products such as electronic resources or for products in which adequate information is unavailable, such as new titles.

Emotion can affect attentional orientation, the elements of the environment to which a selector attends. ${ }^{23}$ Negative stimuli have been found to attract more attention than positive stimuli. Psychologists believe that this may be the result of evolutionary development, which made it necessary to remain attentive to threats to an individual's well-being in order to adapt and survive. Not only will individuals orient more quickly to threats, they appear to be particularly sensitive to threats specifically related to their emotional states. In experiments using a Stroop task, subjects were asked to name the color a word is printed in and ignore its semantic meaning. ${ }^{24}$ Subjects who are afraid of snakes were distracted by words related to snakes such as "venom" or "rattler," while subjects who are socially anxious fixated on words like "outcast" or "ostracize." Thus a selector who is anxious about crime or health or finances may be more attracted to titles having to do with these subjects, may notice them more easily among a group of titles, and may be more predisposed to value them or assign them significance than someone without such an emotional investment.

Psychologists use the "attentional blink" phenomenon to study aspects of the way emotion influences attention. ${ }^{25}$ Attentional blink occurs when a series of visual stimuli are presented in rapid succession, a procedure known as Rapid Serial Visual Presentation (RSVP) ${ }^{26}$ The subject is asked to detect two targets. If the targets are presented in very rapid succession, the subject is no longer able to recognize the second target, provided that it is affectively neutral. If the second target is emotionally arousing (in either a pleasant or unpleasant way), however, detection improves. ${ }^{27}$ This indicates that emotion influences attention, and suggests that in situations in which a selector discovers a title that is emotionally relevant and another title of possible value appears immediately afterward, the selector may be less likely to detect the second title if it does not have the emotional impact or salience of the first title. With much book selection being conducted online these days, a selector using the Barnes and Noble or Amazon database who is searching through a succession of titles on a particular subject and encounters a title of emotional significance may be more prone to overlook another useful but more affectively neutral title if it appears soon after the emotionally important one. That is because the selector's attention has been monopolized or captured by the earlier title. Arousing titles distract attention from titles of potentially equal merit that may be less arousing. They provide a greater resistance to attentional interferences or capture from competing titles, and this resistance manifests itself in the form of temporal persistence. Thus when an affect-laden title is the second target, it enhances awareness and detection, but when it appears as the first target, it may result in a kind of inattentional blindness on the part of selector for the second title.

\section{Mood-Congruent Decision Making}

When selectors are faced with a decision about whether to choose a title for the collection, an important factor in the decision-making process is cognitive capacity. This refers to the amount of cognitive resources that are available to make the decision. If information about the title is inadequate, ambiguous, or outdated, or if too much information or conflicting or contradictory information is available, more cognitive resources will be needed. If competing tasks or time pressure are involved, this will increase the need for cognitive resources.

In circumstances where cognitive resources such as attention, learning, memory, and reasoning are insufficient, research by Schwartz suggests the selector may turn to mood-congruent emotions and associations. ${ }^{28}$ The material is primed to be more accessible to the selector if it matches his or her mood. If the selector is in a negative mood, he or she may more easily recall a negative review of the title than a positive one. If the selector is in a positive mood, a memory of similar titles receiving frequent use may come to mind. A selector will be more likely to evaluate a title positively or negatively and render a favorable or unfavorable decision to the extent that he or she is in a positive or negative mood.

Emotions are involved in decision making in two different ways. Immediate emotions are feelings that are experienced at the time a decision needs to be made. They can affect a selector's decision by having a direct impact (i.e., the way a selector immediately feels about the particular title being considered) or an indirect impact (i.e., the selector happens to have been in a preexisting positive mood 
that day, which is enough to sway him or her to purchase the title despite any immediate reservations he or she may have had). The other way that emotions influence decision making is through expected emotions. This kind of emotion refers to predictions that selectors make about the affective outcome of different action scenarios. The predictions are used in selecting actions designed to enhance positive emotions and minimize negative feelings. ${ }^{29}$ For example, a selector might be considering the purchase of an expensive database, but might also anticipate how disappointed he or she would then feel if the use statistics turn out to be low. In order to avoid experiencing the expected disappointment, the selector might then feel dissuaded from purchasing the database.

Feelings become increasingly important in decisions to the extent that the product is unfamiliar or that information about it is unavailable or ambiguous. In such instances, selectors may turn to emotions to fill in the gap. People faced with difficult or ambiguous decisions may use their emotions as a form of information. They may use their immediate emotions and ask themselves, "How do I feel about it?" and then utilize those feelings in making a decision. ${ }^{30}$ Immediate emotions that are positive are likely to result in a positive evaluation of the product and a decision to purchase it, while negative emotions will favor a negative assessment and a decision to forego purchase.

Emotions resulting from one situation can affect decisions in completely unrelated situations. This is a phenomenon that psychologists term "emotional carryover." ${ }^{31}$ For example, suppose a selector receives news that the university has decided to curtail certain health-care benefits. He or she is angered by the news and, later that day, is faced with a decision about whether to acquire a new electronic encyclopedia. The selector is ambivalent because, although the encyclopedia is a good one, it is also very expensive. The residual anger from the morning's news about the benefits cut contributes to a negative disposition on the part of the selector. As a result, the selector decides not to acquire the encyclopedia.

Different kinds of emotions have different effects on the level of cognitive processing that occurs in decision making. Emotions that are typified by a sense of certainty, such as anger or contentment, result in more reliance on cognitive shortcuts known as heuristics. Emotions that are characterized by a lack of certitude such as anxiety or surprise result in more careful information seeking and analysis. ${ }^{32}$

\section{Mood, Bias, and Stereotyping}

Mood has been shown to have an effect on persuasion and stereotyping. Positive mood will not only predispose an individual to accept persuasive messages, but will also make the person more likely to make use of bias and stereotypes in decisions. In one experiment, happy, neutral, and sad participants were recruited and provided with detailed information about a new model of car. ${ }^{33}$ One version of the information described the car as being a highly prestigious brand while the other depicted it as a less prestigious brand. The results strongly support a connection between mood and stereotyping. Happy subjects were greatly influenced by the prestige of the brand. Sad participants were not affected by the prestige of the brand and tended to focus more on details about the car than its perceived image. The implication is that selectors in an upbeat mood will be more likely to be favorably predisposed toward titles from prestigious publishers and vendors when attempting to decide what to purchase.

Negative mood may also prejudice how a person evaluates a product. Evidence of this effect can be found in a study in which students underwent an introduction designed to make them experience either feelings of contentment or anger. ${ }^{34}$ Once these feelings had been evoked in the students, they were asked to read a restaurant review that they were told came from a newspaper but which had, in fact, been created for the experiment. The review featured an equal number of negative and positive statements about the restaurant. After the moods of the students had been neutralized, they were asked to evaluate the restaurant. Those students who originally read the review in an angry mood rated the restaurant far more negatively than those who read the review in a contented mood. Students who were in an angry mood were also much more likely to recall the negative information about the restaurant, while those in a positive mood were able to remember positive information more readily. In this experiment, mood appeared to have an impact not only on the evaluation process, but also on the memory process. Since reviews of new books or electronic products often play an important role in the selection process, mood may play a role in how selectors interpret reviews and also in how they selectively recall information contained in them.

Mood can also have an effect on the intensity with which a stereotype is held. In one experiment, various means, such as music, were used to induce sad, happy, or neutral moods in a group of Canadian students. ${ }^{35}$ The students were then asked to describe typical personality traits of six ethnic groups who reside in Canada: English Canadian, Native American, Jewish, Pakistani, Chinese, and Arabic. Each subject was asked to list whether he or she thought each trait was socially desirable or undesirable and the percentage of the ethnic group that the subject thought had exhibited that trait. A stereotype score was then calculated for each group based on the traits attributed to the group and the subjects' estimate of the percentage of the group exhibiting that trait. The results indicated that those 
students who were in the sad mood induction group exhibited increased negativity of stereotypes for those groups with negative connotations. Sad subjects rated the negative attributes of these groups as being more undesirable than did happy or neutral students. Ethnic groups that had neutral connotations for the students were not greatly affected by the differences in mood. Interestingly, students in a positive mood and those in a negative mood both rated their own ethnic group highly. The experimenters attributed the result to sad subjects attempting to make themselves feel better by denigrating other ethnic groups while at the same time enhancing the social status of their own group. This suggests that selectors who hold stereotypical views of certain subject areas, authors, or formats may find these magnified when in a negative mood.

Mood may play a greater role in the decision-making process of persons for unusual, atypical, or complex stimuli. Psychologists suspect that since the decision-making process for such targets involves longer and more substantial cognition, there is a greater likelihood that "affect infusion" (the influence of emotions upon cognition) may occur. In contrast, any target or object that is prototypical or otherwise standard can be easily comprehended and understood and thus would require relatively little cognitive processing.

In one experiment, the experimenter used a mood induction process to examine the effect of mood upon memory and recall for atypical objects, in this case unusual fictional characters in a story ${ }^{36}$ Mood turned out to be a significant factor in the amount of information subjects remembered about atypical targets, but not typical ones. Subjects who were in a sad mood had better recall for atypical targets, while subjects in a happy mood were better able to remember typical targets. The experimenter believed that because subjects in a sad mood engage in a more indepth, careful kind of processing, they were better able to recall more unusual complex objects. Conversely, happy subjects, more prone to engage in superficial processing that utilizes heuristic shortcuts, thus found it easier to remember standardized objects.

In a follow-up experiment, subjects were exposed to photographs of couples. ${ }^{37}$ In some photos, the couples were matched in terms of physical attractiveness, while in other photos, the couples were mismatched. The prediction was that the mismatched couples would generate more cognitive processing and also more mood-influenced judgments. The experimenter found that this was true, particularly in the case of mixed race couples, but that it did not prove true for more conventional targets such as same-race couples. The more visible the mismatch between partners, the more cognitive activity occurred and the greater were the effects of mood on thinking. Subjects took longer to process information about unusual couples, remembered information about them better, and made evaluative decisions about them that were significantly more influenced by mood. Based on this evidence, it seems likely that a selector will spend substantially more time and effort in deciding whether or not to select an atypical title. It also seems probable that the decision will depend to a greater degree on the mood of the selector than if the title under consideration were more expected.

\section{Mood Incongruence, Contrast Effect, and Overcorrection}

Although the preceding studies have suggested that individuals' feelings will tend to influence their judgment toward closer alignment with their existing mood, this is not always the case. In occasional instances, what psychologists refer to as a "contrast effect" may occur. ${ }^{38}$ The results of some experiments indicate that subjects induced to feel sad assessed the target more favorably than subjects who were made to feel in a happy mood. Researchers attribute this mood incongruence to a psychological mechanism, contrast effect, which does not invalidate the multitude of previous studies that have found judgment and decision making to be mood-congruent. Rather, it suggests that an additional process may be involved in cases of affective asymmetry, in which negative emotions result in more positive evaluations than positive feelings.

The process that psychologists believe is involved in instances of contrast effect occurs when individuals become conscious that their emotions may influence the evaluation of an object. In an effort to counter this bias, they overcompensate and end up evaluating the object to an opposite extreme of their original feeling. The overcorrection occurs because people tend to overestimate the degree to which their feelings influence their judgment. As a result, they not only exclude their own feelings about the object but also ideas activated by the object to be evaluated. ${ }^{39}$ People's ideas are based on a layperson's estimate of how feelings influence decisions and are thus not necessarily accurate and may be subject to distortion.

Overcorrection was tested in an experiment in which a group of subjects were induced to feel discomfort by holding both their arms out straight for six minutes. ${ }^{40}$ Another group of subjects were asked to rest both their arms comfortably on a table for the same period of time. While this was occurring, the subjects listened to a tape recording of a person reading an autobiographical statement written as part of a job application for a position at the university. When the statement was finished, half of the subjects were asked to rate their feelings and the other half were asked to participate in a word-association task that served as a distraction. Then all the subjects were given a questionnaire that asked them to rate the personal appeal of the job appli- 
cant, and then rate the level of discomfort they experienced in their arms. The results of the experiment indicated that the subjects who were distracted by the word-association task exhibited predictable affective congruence. The more discomfort they experienced, the lower they rated the job applicant. When the subjects were made aware of their feelings, however, they exhibited the contrast effect. The worse they felt, the better they rated the applicant. The subjects who were aware of their discomfort realized that it would bias their judgment and overcorrected for it in their assessments of the applicant.

Some psychologists believe that negative affect is more likely to produce overcorrection than positive affect. ${ }^{41}$ This is because negative affect tends to be associated with higher degrees of cognitive activity. The heightened degree of cognitive activity is said to stem from negative affect signaling the person that something is wrong in the environment and that strategies must be devised to address the problem. Negative emotions also tend to lead to inner-directed introspection, which in turn may lead to heightened sensitivity to negative affect and a corresponding cognitive effort to trigger the contrast effect and corresponding decisional overcorrection.

The psychological research described above suggests that selectors who may be aware that they have a bias either in favor of or against a particular subject area, topic, or author may be vulnerable to the contrast effect. Knowing they have such a prejudice may lead them to attempt to overcompensate for their preferences. Because nonpsychologists are not fully aware of the extent to which their feelings influence their judgment, when they try to achieve more of a balance in their selection decisions they may overcorrect and, ironically, end up shifting the selection balance to the other extreme. For example, the selector who knows he has a strong interest in the theoretical aspects of sociology may be acutely sensitive to this preference. In an effort to compensate for this predilection, the selector may try to place extra emphasis on ordering as many quantitative titles as possible. In years in which the publication of quantitative titles is particularly strong, the selector may actually end up purchasing more quantitative than qualitative titles.

If a selector has an aversion to a particular author, school, or genre, and is faced with a decision regarding whether or not to purchase a work that falls within that vein, the selector may make a conscious attempt to deliberately purchase the title. Because the selector knows he or she is biased against it, that bias may itself constitute the deciding factor in persuading the selector to acquire it. Since many selectors also serve as liaisons to faculty in various departments, the bias may take place at a human level rather than a bibliographic one. Selectors, being human, may have certain feelings, either positive or negative, about faculty within the departments they work with. Since many purchases are made with particular faculty members in mind, if the selector has a marked preference for or an aversion to particular faculty and is conscious of these biases, he or she may try to compensate by purchasing more titles that lie within areas of research of less-favored faculty and, as a result, end up overcorrecting.

\section{Conclusion}

Collection management in general—and decision making for collection development in particular-has been characterized as a highly logical, rational process that is primarily based on cognitive factors like attention, perception, memory, and reasoning. The collection management literature is devoid of discussion of any affective processes that may play a role in collection development decisions. Yet, as this paper has tried to suggest, evidence in the psychological literature suggests that affect does play an important role in judgment and decision processes. The experimental evidence indicates that decision making is not exclusively a cognitive process. Emotions do play a significant role, and this paper suggests that affect may interact with cognition in judgment and decision-making processes related to collection management.

In order to make optimal collection-management decisions, selectors, of course, need to do the proper cognitive work, carefully researching the titles they are considering for purchase and investigating the needs and interests of their potential audience, the faculty, and students. Competing demands on cognitive processes, whether stemming from budgets, deadlines, or other library projects, may be inevitable, so it helps to realize how these may affect decision making. Selectors also need to be aware of their emotions and mood states and keep in mind how these may influence cognitive considerations. Certain emotions, such as positive mood states, may make selectors less critical and evaluative in the decision-making process. Whenever selectors find themselves in this state, they need to be particularly vigilant. Affect may also influence memory, and since memory plays an important role in decisions, selectors need to be wary of selective memory. Emotions and mood may also be a factor in what selectors pay attention to, as well as the kind of product advertising that appeals to them. Selectors need to be alert to emotionally incongruent material. Affect may also play an important role in the selection process when information about the product is unavailable or ambiguous. Sticking to the facts as much as possible will discourage irrational or impulsive purchases. Some selectors may use their feelings as a form of information in selecting a product, asking themselves how they feel about it, or even how they might feel about it. Awareness of feelings is advisable and desirable, but decisions should also be based on the best 
evidence available. Emotions from one situation largely or completely unrelated to selecting a title may nonetheless be carried over into the decision process, and selectors need to learn to compartmentalize their emotions.

Both positive and negative moods and emotions can predispose selectors to various forms of bias in the evaluation and selection process. Unusual or atypical titles may be particularly susceptible to mood influence in the selection process, and selectors need to take this into account when they encounter these titles. Finally, selectors need to be aware of the contrast effect and the problem of overcorrection for selection bias. Understanding this psychological mechanism might make selectors less prone to second-guessing themselves in selection decisions and more circumspect about efforts to correct for biases in their selecting.

This paper suggests important implications for how selectors approach the process of collection development, and for how selectors are trained to do their work. Selectors need to look at collection development as more than simply a logical, left-brained, rational calculus of searching for new titles, weighing their strengths and weaknesses, speculating on their potential use, and then trying to make a selection decision based on all the personal variables that come into play. They instead might try a more phenomenological approach, in which they make an effort to become acutely aware of their emotions and moods, take these into account, and then use them as data that might prove as valuable as understanding the product attributes and the potential audience for it. The psychological evidence regarding the various ways that affect can influence cognition in decision making argues for a more self-aware, introspective approach to selection-one in which a selector's mood states and emotions are potentially of great importance and should be afforded greater weight in the overall process of selection.

Further research is needed on the role that emotion may play in the selection process. Experiments could be designed to determine how much of a factor affect may constitute during the actual process of deciding what gets added to the collection. Many of the psychological experiments discussed in this paper use students as subjects. In demographic terms, students tend to be younger and less educated than librarians, therefore working with a population of librarians to see if similar results obtain would be highly useful. It would also be helpful for the experimental conditions to simulate the actual working conditions of selectors rather than those of the lab.

Understanding that affective processes may be involved in decision making for collection development is not enough. More research needs to be done on the relationship between cognitive and affective processes and how they interact and influence each other. In the years to come, psychologists likely will further explore and refine the nuances of the relationship between thinking and feeling as they affect decision making and choice. Librarians would do well to keep abreast of their research and adapt it to conduct research of their own.

\section{References}

1. Jean Boyer Hamlin, "The Selection Process," in Collection Development in Libraries: A Treatise 2 vols., eds. Robert D. Stueart and George B. Miller Jr. Part A, Foundations in Library and Information Science 10 (Greenwich, Conn.: JAI Pr., 1980), 185-201.

2. Ross Atkinson, "The Citation as Intertext: Toward a Theory of the Selection Process," Library Resources \& Technical Services 28, no. 2 (1984): 109-19.

3. John Rutledge and Luke Swindler, "The Selection Decision: Defining Criteria and Establishing Priorities," College \& Research Libraries 48, no. 2 (1987): 123-31.

4. Beatrice Kovacs, The Decision-Making Process for Library Collections: Case Studies in Four Types of Libraries (New York: Greenwood, 1990).

5. Lynn B. Williams, “Subject Knowledge for Subject Specialists: What the Novice Bibliographer Needs to Know," Collection Management 14, no. 3/4 (1991): 31-47.

6. Robert M. Losee Jr., "Optimality and the Best Collection: The Goals and Rules of Selectors and Collection Managers," Collection Management 14, no. 3/4 (1991): 21-30.

7. G. Edward Evans, Developing Library and Information Center Collections, 4th ed. (Greenwood Village, Colo.: Libraries Unlimited, 2000).

8. Peter Clayton and G. E. Gorman, Managing Information Resources in Libraries: Collection Management in Theory and Practice (London: Library Assoc. Pubs., 2001).

9. Peggy Johnson, Fundamentals of Collection Development and Management (Chicago: ALA, 2004).

10. Peter M. Senge, The Fifth Discipline: The Art and Practice of the Learning Organization (New York: Doubleday/ Currency, 1990).

11. Oliver H. Turnbull, Helen Berry, and Cathryn E. Y. Evans, “A Positive Emotional Bias in Confabulatory False Beliefs about Place," Brain \& Cognition 55, no. 3 (2004): 490-94.

12. Richard S. Lazarus, "The Cognition-Emotion Debate: A Bit of History," in Handbook of Cognition and Emotion, ed. Tim Dalgleish (New York: Wiley, 1999), 3-19.

13. Eric Klinger, "Effects of Motivation and Emotion on Thought Flow and Cognition: Assessment and Findings," in Personality Research, Methods, and Theory: A Festschrift Honoring Donald W. Fiske, eds. Patrick E. Shrout and Susan T. Fiske (Hillsdale, N.J.: Lawrence Erlbaum Assoc., 1995), 257-70.

14. Baba Shiv and Alexander Fedorikhin, "Heart and Mind in Conflict: The Interplay of Affect and Cognition in Consumer Decision Making," Journal of Consumer Research 26, no. 3 (1999): 278-92.

15. Joseph P. Forgas, "Introduction: Affect and Social Cognition," in Handbook of Affect and Social Cognition, ed. Joseph P. Forgas (Mahwah, N.J.: Lawrence Erlbaum Assoc., 2001), 1-24; Diane M. Mackie and Leila T. Worth, "Feeling Good, 
But Not Thinking Straight: The Impact of Positive Mood on Persuasion," in Emotion and Social Judgments, ed. Joseph P. Forgas (Oxford, England: Pergamon Pr., 1991), 201-19.

16. Miriam Burke and Andrew M. Mathews, "Autobiographical Memory and Clinical Anxiety," Cognition and Emotion 6, no. 1 (1992): 23-35.

17. Philip C. Watkins, "Unconscious Mood-Congruent Memory Bias in Depression," Journal of Abnormal Psychology 105, no. 1 (1996): 34-41.

18. John D. Mayer, Laura J. McCormick, and Sara E. Strong, "Mood-Congruent Memory and Natural Mood: New Evidence," Personality \& Social Psychology Bulletin 21, no. 7 (1995): 736-46.

19. William R. Doherty, "Emotional Contagion and Social Judgment," Motivation and Emotion 22, no. 3 (1998): 187209.

20. Meryl P. Gardner, "Responses to Emotional and Informational Appeals: The Moderating Role of Context-Induced Mood States," in Attention, Attitude, and Affect in Response to Advertising, eds. Eddie M. Clark, Timothy C. Brock, and David W. Stewart (Mahwah, N.J.: Lawrence Erlbaum Assoc., 1994), 207-21.

21. Georgios A. Bakamitsos and George J. Siomkas, "Context Effects in Marketing Practice: The Case of Mood," Journal of Consumer Behavior 3, no. 4 (2004): 304-14.

22. Tokihiro Ogawa and Naoto Suzuki, "On the Saliency of Negative Stimuli: Evidence from Attentional Blink," Japanese Psychological Research 46, no. 1 (2004): 20-30.

23. Douglas Derryberry and Don M. Tucker, "Motivating the Focus of Attention," in The Heart's Eye: Emotional Influences in Perception and Attention, eds. Paula M. Niedenthal and Shinobu Kitayama (San Diego: Academic, 1994), 167-96.

24. Andreas Keil and Niklas Ihssen, "Identification Facilitation for Emotionally Arousing Verbs During the Attentional Blink," Emotion 4, no. 1 (2004): 23-35.

25. Laetitia Silvert et al., "Emotional Stimuli in Rapid Serial Visual Presentation," Visual Cognition 11, no. 4 (2004): 433-60.

26. Adam K. Anderson, "Affective Influences on the Attentional Dynamics Supporting Awareness," Journal of Experimental Psychology: General 134, no. 2 (2005): 258-81.

27. Norbert Schwartz, "Emotion, Cognition, and Decision Making," Cognition and Emotion 14, no. 4 (2000): 433-40.

28. George Loewenstein and Jennifer S. Lerner, "The Role of Affect in Decision Making," in Handbook of Affective Sciences, eds. Richard J. Davidson, Klaus R. Scherer, and H. Hill Goldsmith (New York: Oxford Univ. Pr., 2003), 619-42.

29. Gerald L. Clore, Norbert Schwarz, and Michael Conway, "Affective Causes and Consequences of Social Information
Processing," in Handbook of Social Cognition, 2nd ed., vol. 1, Basic Processes, eds. Robert S. Wyer Jr., and Thomas K. Srull (Hillsdale, N.J.: Lawrence Erlbaum Assoc., 1994), 323-417.

30. Rajagopal Raghunathan and Michel Tuan Pham, "All Negative Moods Are Not Equal: Motivational Influences of Anxiety and Sadness on Decision Making," Organizational Behavior and Human Decision Processes 79, no. 1 (1999): 56-77.

31. Larissa Z. Tiedens and Susan Linton, "Judgment under Emotional Certainty and Uncertainty: The Effects of Specific Emotions on Information Processing," Journal of Personality \& Social_Psychology 81, no. 6 (2001): 973-88.

32. Herbert Bless and Eric R. Igou, "Mood and the Uses of General Knowledge Structures in Judgment and Decision Making," in The Routines of Decision Making, eds. Tilmann Betsch and Susanne Haberstroth (Mahwah, N.J.: Lawrence Erlbaum Assoc., 2005), 193-210.

33. Gordon H. Bower and Joseph P. Forgas, "Affect, Memory and Social Cognition," in Cognition and Emotion, eds. Erich Eich et al. (London: Oxford Univ. Pr., 2000), 87-168.

34. Victoria M. Esses, Geoffrey Haddock, and Mark P. Zanna, "Values, Stereotypes, and Emotions as Determinants of Intergroup Attitudes," in Affect, Cognition, and Stereotyping: Interactive Processes in Group Perception, eds. Diane M. Mackie and David Lewis Hamilton (San Diego: Academic, 1993), 137-66.

35. Joseph P. Forgas, “On Bad Mood and Peculiar People: Affect and Person Typicality in Impression Formation," Journal of Personality and Social Psychology 62, no. 5 (1992): 863-75.

36. Joseph P. Forgas and Stephanie J. Maylan, "Affective Influences on Stereotype Judgments," Cognition and Emotion 5, no. 5/6 (1991): 379-95.

37. Leonard Berkowitz et al., "On the Correction of FeelingInduced Judgmental Biases," in Feeling and Thinking: The Role of Affect in Social Cognition, ed. Joseph P. Forgas (New York: Cambridge Univ. Pr., 2000), 131-52.

38. Duane T. Wegener and Richard E. Petty, "The Flexible Correction Model: The Role of Naïve Theories of Bias in Bias Correction," in Advances in Experimental Social Psychology, vol. 29, ed. Mark P. Zanna (San Diego: Academic, 1997), 141-208.

39. Leonard Berkowitz and Bartholomeu T. Troccoli, "Feelings, Direction of Attention, and Expressed Evaluations of Others" Cognition \& Emotion 4, no. 4 (1990): 305-25.

40. Joanne V. Wood, Judith A. Saltzberg, and Lloyd A. Goldsamt, "Does Affect Induce Self-Focused Attention?" Journal of Personality and Social Psychology 58, no. 5 (1990): 899-908.

41. Ibid. 